\title{
Optimization of the degradation of organic complexants by Wet Air Oxidation
}

\author{
S. Bachir ${ }^{1, *}$, M. Ambrosio ${ }^{1}$, V. Federici ${ }^{2}$ and H. Barnier ${ }^{2}$ \\ ${ }^{1}$ Laboratoire de Chimie et Environnement, 3 Place Victor Hugo, Case 29, 13331 Marseille, France \\ ${ }^{2}$ CEA centre de Cadarache, Saint-Paul-Les-Durance, France
}

\begin{abstract}
The Wet Air Oxidation of four organic complexants was studied. This study focuses on the determination of the main by-products formed and the optimization of the degradation yield in a defined area according to four parameters, which are reaction temperature, initial substrate concentration, reaction time and oxygen partial pressure. This optimization is followed by a classic Doehlert matrix.
\end{abstract}

Key words. Organic complexants - total organic carbon - Wet Air Oxidation - intermediates - mineral by-products optimization, experimental design.

\section{Introduction}

The nuclear industry employes many organic complexant solutions in the different stages of the extraction and purification of the nuclear fuel. The wastes resulting from this process are very complex and need specific and efficient treatment methods. A given waste treatment should take into account the technique efficiency and operating costs. From this perspective, the research and development of reliable waste valorization and/or destruction technologies prove to be essential in order to extract the valorizable share, and/or the reduction of the polluting or harmful character of the wastes. To this end, techniques such as acid digestion, electrical reactors, supercritical oxidation or subcritical wet oxidation are currently tested on a laboratory scale or industrial pilot [1-5].

In this paper we study the treatment of nuclear wastes by subcritical wet oxidation. The principle of this process relies on the literal combustion of the organic matter at a relatively high temperature and pressure. This technique has many advantages over other conventional waste treatment techniques such as the incineration or biodegradation ones [6,7]:

- Fast oxidation of the wastes and by-products formed.

- The gaseous effluents formed during the process are cleaner than those produced in the incineration process. The operating conditions eliminate the formation of dioxins and other polluting gases $\left(\mathrm{NO}_{x}, \mathrm{SO}_{2}\right)$.

- An energy recovery is also possible and in some cases, a valorization of the by-products.

- The operating costs of the installation are lower compared to the ones of the incineration process.

Many tests on different types of wastes have been reported in several publications. The control of the different degradation parameters and the perfect knowledge of the reaction mechanisms are essential for a better optimization of the oxidation efficiency. The study of model compounds allows the understanding of these mechanisms and their application to real wastes. Because of this, there are many results published about pure compounds [8-14] but very few concerning nuclear waste effluents.

The aim of this paper is the destruction of the organic matter of radioactive waste. The tests were conducted on four model compounds, which are tridodecylamine, tributylphosphate, ethylenediaminetetraacetic acid and trifluorothenoylacetone. These compounds are used in the separation and purification phases of the nuclear fuel (Uranium, Thorium, and Plutonium).

This study is divided in two parts. Firstly, the degradability of the substrates is followed versus the reaction temperature in order to determine the main refractory by-products formed and follow the behavior of the heteroatoms contained in the structures of these molecules. The second part is devoted to the modelization of the reaction in order to predict in a determined area the degradation yield at each point. For this modelization we used the uniform Doehlert matrix with four factors, which are reaction temperature, initial substrate concentration, reaction time and air pressure.

\section{Materials and analytical methods}

\section{Equipment}

The tests were carried out in laboratory batch installation schematized in scheme 1. This installation includes:

- A 500-mL autoclave equipped with an agitator and a thermocouple. This autoclave is placed in an electrical oven and kept hermetically shut by twelve screws.

- Liquid and gas sample lines equipped with a cooling system and a condensation pot.

* Correspondence and reprints

Received June 19, 1998; revised August 25, 1998; accepted September 1, 1998. 


\section{Original articles}

- Gas inlet system composed of two lines: the oxidizing mixture $\left(50 \% \mathrm{~N}_{2} / 50 \% \mathrm{O}_{2}\right)$ line and the low pressure nitrogen line to purge the reactor before the experiment.

- A safety system with an electrovalve and a rupture disc. The opening of the electrovalve (which allows the disposal of the system) is activated when the pressure or temperature reaches the threshold set by the operator.

\section{Experimental protocol}

$300-\mathrm{mL}$ of the aqueous substrate solution were introduced into the reactor which is then closed hermetically. This volume constitutes $2 / 3$ of the reactor useful volume. Nitrogen gas was bubbled into the autoclave to drive off air. After programming the oven, the agitation started and the reactor was heated up to a pre-established reaction temperature. Once this temperature was reached, the oxidant was bubbled into the vessel. It is assumed that the reaction time starts since the introduction of the oxidant. In order not to disturb the reaction, no liquid or gaseous samples were withdrawn during the experiment. At the end of the operation, the reactor is rapidly cooled down and the liquid effluent was recovered for physicochemical analyses.

\section{Analytical techniques}

The degradation yield is calculated according to the total organic carbon (TOC) at the initial and final states in the liquid effluent by the following expression:

$$
\Delta \mathrm{TOC}=\frac{[\mathrm{TOC}]_{\text {in }}-[\mathrm{TOC}]_{\mathrm{f}}}{[\mathrm{TOC}]_{\text {in }}} \times 100 .
$$

The following methods were used to analyze the final effluent resulting from the substrate oxidation:

A TOC 5050 Shimadzu analyzer was used to determine the total organic carbon (TOC). The principle of the analysis relies on the measurement of the total carbon (TC) and the inorganic carbon (IC) following two distinctive ways. The TC is obtained by the air oxidation catalyzed by platinum and the IC, by reaction with phosphoric acid. The $\mathrm{CO}_{2}$ thus formed is detected by infrared. An integrated system allows the calculation of the TOC concentration $(\mathrm{TOC}=\mathrm{TC}-\mathrm{IC})$. The calibration is conducted with a mixture solution of potassium phtalate and hydrogenophtalate.

The high performance liquid chromatography (HPLC) was used to determine sodium and ammonium ions, and trifluorothenoylacetone. A Waters pump was used with a $1 \mathrm{~mL} \mathrm{~min}^{-1}$ flow. The determination of sodium and ammonium ions was carried out with an IC PAK cation N/D column $(15 \mathrm{~cm}$ length) that functions with a nitric acid $(3 \mathrm{mM})$ and EDTA $(0.1 \mathrm{mM})$ mixture solution. The detection was insured by a Waters 510 conductimeter. The determination of trifluorothenoylacetone was conducted with a Novapak $\mathrm{C}_{18}$ column (15 cm length). The elution is done with acetonitrile $(50 \%)$ and water $(50 \%)$ mixture. The detection is done at $235 \mathrm{~nm}$ with a Varian spectrophotometer.

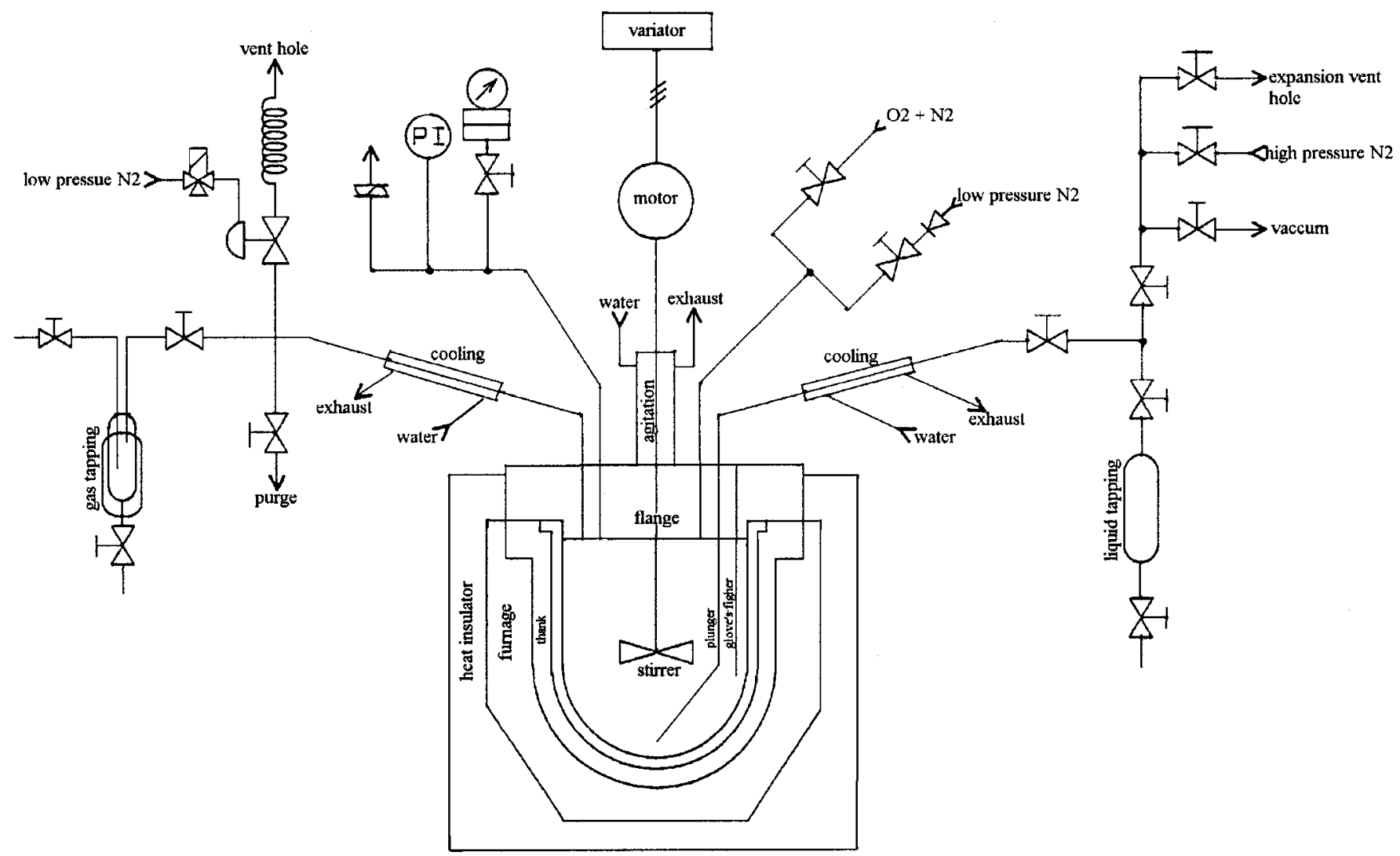

Scheme 1. Schematic diagram of the experimental setup. 


\section{Original articles}

Gaseous phase chromatography (CPG): The determination of organic compounds resulting from the degradation of the substrate was conducted on a Hewlett Packard 5890 series 2 chromatograph equipped with a capillary $C P-S I L$ $5 C B$ fused Silica WCOT column (Film 5 microns $0.32 \mathrm{~mm}$ internal diameter and $25 \mathrm{~m}$ length). This column has great separation efficiency and it appreciably reduces the retention times of the compounds. A Flame Ionization Detector (FID) was employed as detector. The gradient of temperature allows a good separation of all of the compounds. In this case, the column is programmed to $100{ }^{\circ} \mathrm{C}$ during 5 minutes to separate acetone, methanol, butanol and dodecane, then this temperature is risen up to $170{ }^{\circ} \mathrm{C}$ to allow the detection of trifluorothenoylacetone and TBP. The concentrations of the compounds were estimated versus a calibration process by the Chemstation software.

A DIONEX DX 100 ionic chromatograph that links up an ion exchange with a conductimetric detection was used for the determination of mineral anions and low molecular weight organic acids (formic and acetic acids). The separation column was an AS 4 type composed of a quaternary ammonium resin in hydroxyl form and where the elution is carried out by sodium carbonate $\left(1.7 \mathrm{mmol} \mathrm{\textrm {L } ^ { - 1 } )}\right.$ and hydrogenocarbonate $\left(1.7 \mathrm{mmol} \mathrm{L}^{-1}\right)$ solution mixture, or by sodium borate $(5 \mathrm{mM})$ solution.

\section{Results and discussion}

\section{Degradation tests}

The tests were conducted with $5 \mathrm{~g} \mathrm{~L}^{-1}$ substrate solution. The reaction temperatures were $260^{\circ} \mathrm{C}, 280^{\circ} \mathrm{C}, 300^{\circ} \mathrm{C}$ and $320^{\circ} \mathrm{C}$, respectively. The oxygen partial pressure introduced for each test is approximately 30 bars (60 bars of air containing $50 \%$ of $\mathrm{N}_{2}$ and $50 \%$ of $\mathrm{O}_{2}$ ). The agitation speed and the reaction time were kept at $500 \mathrm{rpm}$ and 30 minutes, respectively. $1.5 \mathrm{~g}$ sodium carbonate were introduced into the initial solution to prevent the acidification of the reaction medium and limit the corrosion effect due to the formation of some mineral acids in solution.

\section{Degradation of compounds}

The degradation yields varies according to the nature of the substrate and the reaction temperature (Fig. 1). The EDTA and the mixture tributylphosphate $(30 \%)$ /dodecane $(70 \%)$ are the most easily degradable in comparison to trifluorothenoylacetone (TTA) and tridodecylamine. Thus, at $260{ }^{\circ} \mathrm{C}$ we obtained a $62 \%$ degradation yield for EDTA versus $50 \%$ for TTA and $58 \%$ for tridodecylamine (TDA). This difference in degradation yield is more perceptible at a higher temperature $\left(320{ }^{\circ} \mathrm{C}\right)$ where we found $89 \%$ for $E D T A$ versus $78 \%$ for $T T A$ and only $67 \%$ for the tertiary amine. The degradation yield of tridodecylamine is the lowest one. This can be explained on the one hand by the high proportion of organic carbon $(82 \%)$, and on the other hand, by the quantity of oxygen injected which is inferior to the stoichiometrical quantity necessary for a complete oxidation of this substrate. Concerning tributylphosphate, the TOC yields are better in the case of the mixture TBP/dodecane ( $80 \%$ at $260{ }^{\circ} \mathrm{C}$ and $90 \%$ at $320^{\circ} \mathrm{C}$ ) than in the case of tributylphosphate alone $\left(58 \%\right.$ at $260{ }^{\circ} \mathrm{C}$ to $82 \%$ at $\left.320^{\circ} \mathrm{C}\right)$. This can be explained by the refractory character of

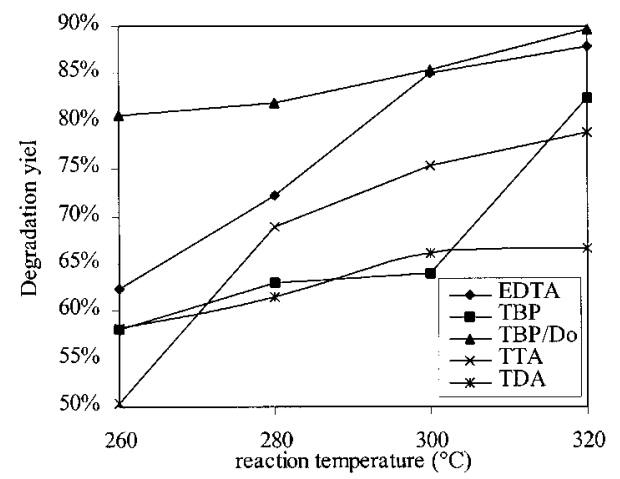

Fig. 1. Variation of the TOC yield versus the reaction temperature.

1-butanol. Indeed, this by-product is the main one formed and its complete oxidation is significant only at reaction temperatures higher than $300{ }^{\circ} \mathrm{C}$.

In a general way, the yield variation versus reaction temperature is marked up to $300{ }^{\circ} \mathrm{C}$ of reaction temperature. The yields vary slowly between $300{ }^{\circ} \mathrm{C}$ and $320^{\circ} \mathrm{C}$.

\section{Reaction by-products}

The global degradation process of the substrates is slowed down by the formation of reaction by-products, which are more or less oxidizable. The natures of these by-products as well as their respective concentrations in the final effluents are a function of the substrate structure and reaction temperature. The major compounds found are acetic and formic acids, acetone, methanol and 1-butanol. The 1-butanol is found only in the effluents resulting from the tributylphosphate oxidation.

The degradation of EDTA ends with the formation of acetic and formic acids, and methanol. The proportions of these by-products in the final TOC are shown in figure 2. Between $260{ }^{\circ} \mathrm{C}$ and $300{ }^{\circ} \mathrm{C}$, the acetic and formic acids resulting from the degradation of the initial substrate decrease considerably before reaching a plateau. The methanol proportion increases from $260{ }^{\circ} \mathrm{C}$ to $280{ }^{\circ} \mathrm{C}$ and later significantly decreasing up to $320^{\circ} \mathrm{C}$. Table I recapitulates the contribution of these by-products in the final TOC determined. The non-degraded substrate and traces of unidentified by-products with smaller hydrocarbon chains constitute the rest of this proportion.

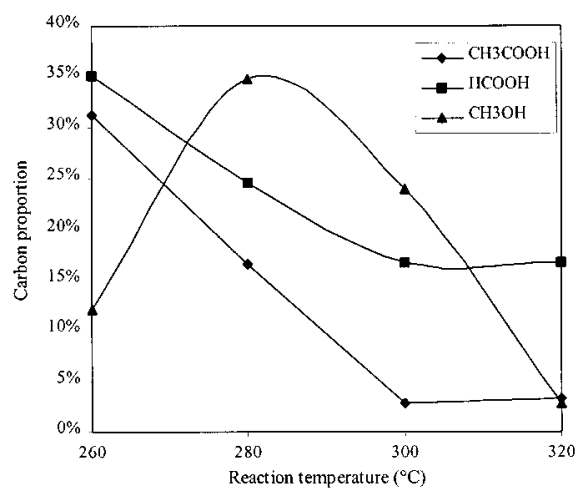

Fig. 2. Degradation of EDTA: variation of the organic carbon proportion transformed into identified byproducts in the final effluents. 


\section{Original articles}

The tributylphosphate yields essentially 1-butanol. The other by-products are found in smaller concentrations (Fig. 3). The reduction of 1-butanol concentration versus the reaction temperature is accompanied by an increase of the concentrations of acetic and formic acids, which indicates a production of these acids from the oxidation of 1-butanol.

The degradation of trifluorothenoylacetone yields mainly acetic acid and acetone. Figure 4 shows the variation of the proportions of these by-products in the final effluents versus reaction temperature. We observe an increase of acetic acid concentrations as the oxidation temperature increases. While, on the contrary, acetone concentrations decrease; a more important destruction of the initial substrate as the temperature rises and the oxidation of the acetone that is formed can interpret this. The high proportion

Table I. Proportion of the organic carbon in identified by-products in the final effluent.

\begin{tabular}{lccccc}
\hline $\begin{array}{l}\text { Reaction } \\
\text { temperature }\end{array}$ & EDTA & TDA & TTA & TBP & $\begin{array}{c}\text { TBP/ } \\
\text { Dodecane }\end{array}$ \\
\hline $260{ }^{\circ} \mathrm{C}$ & $82.25 \%$ & $25.81 \%$ & $54.17 \%$ & $84.26 \%$ & $77.85 \%$ \\
$280{ }^{\circ} \mathrm{C}$ & $75.69 \%$ & $31.18 \%$ & $92.84 \%$ & $93.04 \%$ & $78.44 \%$ \\
$300{ }^{\circ} \mathrm{C}$ & $43.42 \%$ & $46.53 \%$ & $85.85 \%$ & $47.89 \%$ & $71.81 \%$ \\
$320{ }^{\circ} \mathrm{C}$ & $22.68 \%$ & $44.61 \%$ & $91.55 \%$ & $42.18 \%$ & $50.67 \%$ \\
\hline
\end{tabular}

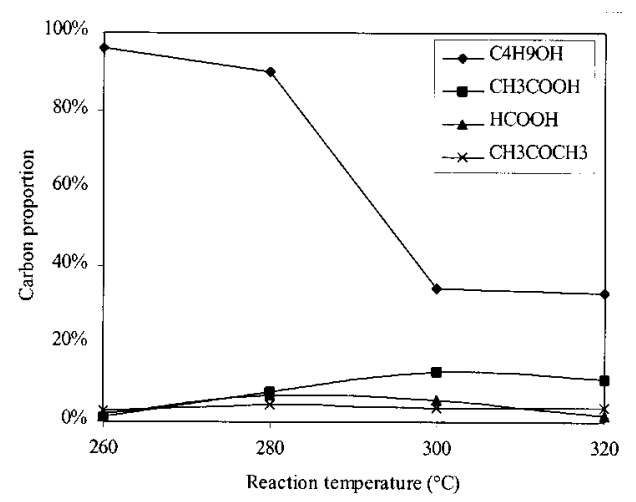

Fig. 3. Degradation of TBP: Variation of the organic carbon proportion transformed into identified byproducts in the final effluents.

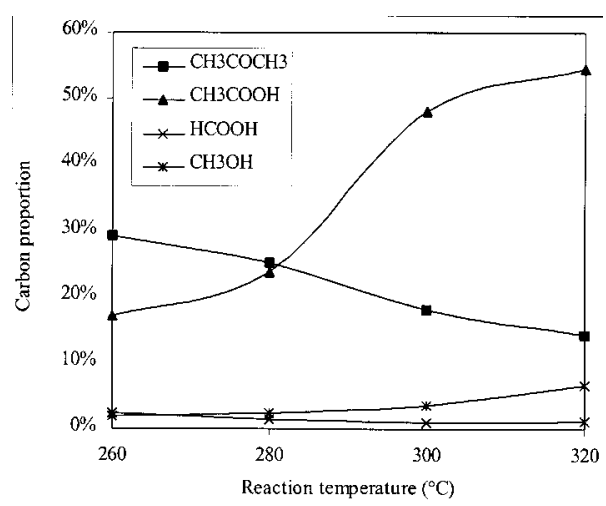

Fig. 4. Degradation of TTA: Variation of the organic carbon proportion transformed into identified byproducts in the final effluents. of acetic acid contributes to diminish the global degradation yield. Indeed, this by-product is known to be the most refractory one in WAO. Foussard et al. [15] observed that its complete oxidation was significant only at a reaction temperature higher than $300{ }^{\circ} \mathrm{C}$, and among the organic acids, the acetic acid is the one with the highest activation energy and that it decreases as the length of the hydrocarbon chain increases.

The degradation of tridodecylamine ends with the formation of several unidentified by-products; consequently, the degradation yield is lower.

\section{The behaviors of the heteroatoms}

The transformation of the heteroatoms can be summarized as follows:

- Fluorine is transformed into fluoride ions $\left(\mathrm{F}^{-}\right)$.

- Sulfur is transformed into sulfate ions $\left(\mathrm{SO}_{4}^{2-}\right)$. No trace of $\mathrm{SO}_{2}$ was detected in the gaseous phase. The sulfur mass balance shows that practically the whole sulfur liberated by the degradation of the initial substrate is found in the $\mathrm{SO}_{4}^{2-}$ form.

- The phosphorus present in tributylphosphate is transformed into phosphate ions $\left(\mathrm{PO}_{4}^{3-}\right)$.

- The organic nitrogen follows three possible pathways: 1) reduction to nitrogen gas; 2) reduction to ammonium ions; 3 ) oxidation to nitrites and further to nitrates. The reaction of reduction is predominant although we are in an oxidizing medium. Other authors have observed the reduction of the organic nitrogen into ammonium ions $[16,17]$. $\mathrm{NH}_{4}^{+}$ions constitute 90 to 98 percent of the nitrogen in the final effluent. Nitrate and nitrite ions are present in very small proportions (Tab. II). We have observed in the best cases no more than $50-\mathrm{mg} \mathrm{L}^{-1}$ of these ions, which correspond to less than $1 \%$ of the initial organic nitrogen. This can be explained by the fact that the thermodynamical hindrance of the nitrogen oxidation to nitrite and further to nitrate is not satisfied. No nitrogenous oxide $\left(\mathrm{NO}_{x}\right)$ was detected in the gaseous samples taken at the end of the experiment on EDTA and tridodecylamine. Figure 5 shows the variation of the proportions of the initial nitrogen transformed into the ammoniacal form according to the reaction temperature. The maximum transformation is obtained at $280^{\circ} \mathrm{C}$ with $70 \%$. The nitrogen balance shows that a non-negligible quantity of nitrogen (15 to $35 \%$ ) is transformed into gaseous $\mathrm{N}_{2}$.

Table II. Concentration of the mineral by-products in the final effluents.

\begin{tabular}{lccccccccc}
\hline $\begin{array}{l}\text { Reaction } \\
\text { temperature }\end{array}$ & {$\left[\mathrm{NO}_{3}^{-}\right]$} & $\mathrm{EDTA}$ & \multicolumn{2}{c}{$\mathrm{TDA}$} & \multicolumn{2}{c}{$\mathrm{TTA}$} \\
& {$\left[\mathrm{NO}_{2}^{-}\right]$} & {$\left[\mathrm{NH}_{4}^{+}\right]$} & {$\left[\mathrm{NO}_{3}^{-}\right]\left[\mathrm{NO}_{2}^{-}\right]\left[\mathrm{NH}_{4}^{+}\right]$} & {$\left[\mathrm{F}^{-}\right]$} & {$\left[\mathrm{SO}_{4}^{2-}\right]$} \\
\hline $260{ }^{\circ} \mathrm{C}$ & 6.24 & 29.22 & 336.3 & 17.28 & - & 50 & 686.76 & 1005.95 \\
$280^{\circ} \mathrm{C}$ & 3.67 & 25.14 & 427.2 & 20.28 & - & 86.7 & 713.52 & 1900.14 \\
$300^{\circ} \mathrm{C}$ & 7.63 & 46.8 & 411.8 & 6.76 & - & 140 & 900.82 & 2049.18 \\
$320{ }^{\circ} \mathrm{C}$ & 51.32 & 12.22 & 409.0 & 26.29 & - & 150 & 990.01 & 2172.72 \\
\hline
\end{tabular}




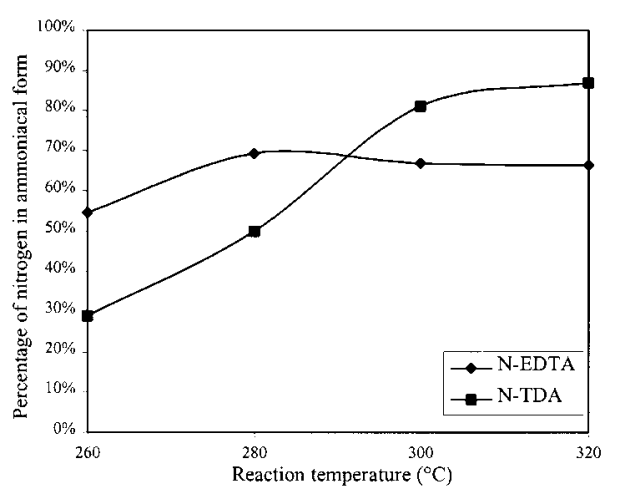

Fig. 5. Evolution of initial nitrogen proportion transformed into ammoniacal nitrogen.

\section{Optimization of degradation yields}

Several factors are capable of influencing the reaction at different degrees. The optimal combination of all of these factors allows to obtain the best degradation yield. To determine this combination, we chose a second degree mathematical model. The experiments were carried out according to a classic Doehlert matrix. This model has the advantage of having great construction simplicity and good qualities of the matrix [18]. The substrate used for this modelization is trifluorothenoylacetone. The factors and the experimental area are shown in table III. The volume of the solution and the agitation speed are fixed at $300 \mathrm{~mL}$ and $500 \mathrm{rpm}$, respectively. The experimental design is given in table IV.

\section{Results}

The statistical analysis of the results by means of the Nemrod software [19] leads to the following equation:

$Y_{1}=71.90+17.25 \times X_{1}-9.37 \times X_{2}+3.37 \times X_{3}+3.85 \times$ $X_{4}-10.50 \times\left(X_{1} \times X_{1}\right)-6.35 \times\left(X_{2} \times X_{2}\right)+1.42 \times\left(X_{3} \times X_{3}\right)$ $+3.46 \times\left(X_{4} \times X_{4}\right)+1.92 \times\left(X_{1} \times X_{2}\right)-4.79 \times\left(X_{1} \times X_{3}\right)+$ $2.34 \times\left(X_{2} \times X_{3}\right)-1.03 \times\left(X_{1} \times X_{4}\right)-2.70 \times\left(X_{2} \times X_{4}\right)+0.84$ $\times\left(X_{3} \times X_{4}\right)$.

The graphical representation of the results permits a better visualization of the effects of the different factors. Figure 6 shows the factor's progression for the maximization of yield. We observe that the optimal path goes through a diminution of the initial substrate concentration $\left(X_{2}\right)$ and an increase of the reaction temperature $\left(X_{1}\right)$, reaction time $\left(X_{3}\right)$ and oxygen partial pressure $\left(X_{4}\right)$.

The increment of the factor's levels does not have the same effect according to any specific case. The reaction temperature has a markedly progressive effect and it allows to reach an $80 \%$ yield around $290^{\circ} \mathrm{C}$. However, this effect becomes stable around $300{ }^{\circ} \mathrm{C}$. This means that in experiments conducted at $300{ }^{\circ} \mathrm{C}$ and $320{ }^{\circ} \mathrm{C}$ there is little difference in TOC yield. The $20^{\circ} \mathrm{C}$ difference does not have the same effect in a lower temperature area. There is a significant yield variation between $240{ }^{\circ} \mathrm{C}$ and $280{ }^{\circ} \mathrm{C}$.

The increase of the reaction time is negligible all along the optimal path, where it is supposed that 40 minutes are sufficient to obtain a very good degradation yield. The oxygen partial pressure $\left(X_{4}\right)$ was increased (37 bars of
Table III. Degradation of TTA: factors and experimental area.

\begin{tabular}{lccc}
\hline Variables & Factors & Center & Variation pace \\
\hline$X_{1}$ & Reaction temperature & $280{ }^{\circ} \mathrm{C}$ & $40{ }^{\circ} \mathrm{C}$ \\
$X_{2}$ & Substrate concentration & $5 \mathrm{~g} \mathrm{~L}^{-1}$ & $4.618 \mathrm{~g} \mathrm{~L}^{-1}$ \\
$X_{3}$ & Reaction time & 40 minutes & 20 minutes \\
$X_{4}$ & Air pressure & 60 bars & 30 bars \\
\hline
\end{tabular}

Table IV. The experimentation plan of the Doehlert matrix.

\begin{tabular}{cccccc}
\hline$N^{\circ}$ trial & $\begin{array}{c}\text { Temperature } \\
\left({ }^{\circ} \mathrm{C}\right)\end{array}$ & $\begin{array}{c}\text { Substrate }]_{i n} \\
\left(\mathrm{~g} \mathrm{~L}^{-1}\right)\end{array}$ & $\begin{array}{c}\text { Time } \\
(\text { min })\end{array}$ & $\begin{array}{c}P_{\text {air }} \\
(\text { bars })\end{array}$ & $\begin{array}{c}\text { Response } \\
Y_{1}\end{array}$ \\
\hline 1 & 320 & 5.000 & 40 & 60 & $80.56 \%$ \\
2 & 240 & 5.000 & 40 & 60 & $42.25 \%$ \\
3 & 300 & 9.000 & 40 & 60 & $70.17 \%$ \\
4 & 260 & 1.000 & 40 & 60 & $60.53 \%$ \\
5 & 300 & 1.000 & 40 & 60 & $82.11 \%$ \\
6 & 260 & 9.000 & 40 & 60 & $45.26 \%$ \\
7 & 300 & 6.334 & 57 & 60 & $72.33 \%$ \\
8 & 260 & 3.665 & 23 & 60 & $64.81 \%$ \\
9 & 300 & 3.665 & 23 & 60 & $78.42 \%$ \\
10 & 280 & 7.665 & 23 & 60 & $57.55 \%$ \\
11 & 260 & 6.334 & 57 & 60 & $65.43 \%$ \\
12 & 280 & 2.334 & 57 & 60 & $81.71 \%$ \\
13 & 300 & 6.334 & 45 & 83,75 & $78.37 \%$ \\
14 & 260 & 3.665 & 35 & 36,27 & $61.64 \%$ \\
15 & 300 & 3.665 & 35 & 36,27 & $77.34 \%$ \\
16 & 280 & 7.665 & 35 & 36,27 & $65.24 \%$ \\
17 & 280 & 5.000 & 53 & 36,27 & $72.13 \%$ \\
18 & 260 & 6.334 & 45 & 83,75 & $65.15 \%$ \\
19 & 280 & 2.334 & 45 & 83,75 & $80.96 \%$ \\
20 & 280 & 5.000 & 27 & 83,75 & $76.25 \%$ \\
21 & 280 & 5.000 & 40 & 60 & $71.31 \%$ \\
22 & 280 & 5.000 & 40 & 60 & $70.34 \%$ \\
23 & 280 & 5.000 & 40 & 60 & $74.06 \%$ \\
\hline & & & & & \\
\hline
\end{tabular}

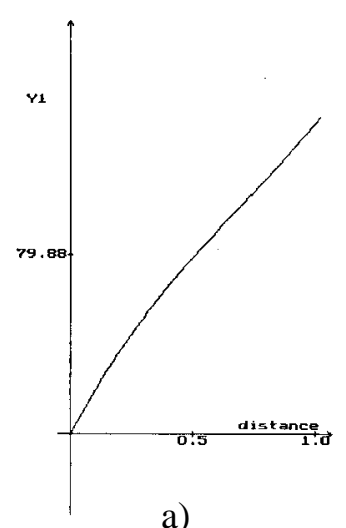

a)

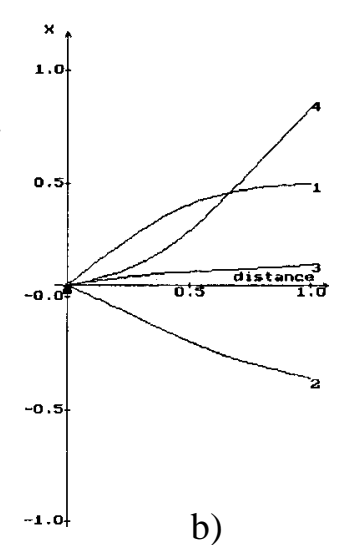

b)
Fig. 6. WAO of trifluorothenoylacetone: Optimal paths. a) Maximization of the TOC yield. b) Variation of the factors. 


\section{Original articles}

oxygen partial pressure) to get a better degradation of the substrates.

The isoresponse curves (Figs. 7-9) show the variation of yields as a function of the factors' variation. These curves practically have the same shape: below the experimental area center $(X<0)$, the curves are relatively closed one another, which confirms the preponderant influence of the temperature on the yield in this area. Next to the area center and above it, the same curves become increasingly separated confirming a relative stabilization of the temperature's influence.

\section{Interpretation of the factor effects}

The wet air oxidation is known to follow a free radical mechanism $[8,20]$. The chemical bond's breaking is under the direct influence of the reaction temperature. Higher temperatures will provide enough energy for the bond's breaking. The more the reaction temperature is raised, the more the necessary energy for this breakage is sufficient. The action of the temperature on the TOC yield is decisive in the $240{ }^{\circ} \mathrm{C}-280{ }^{\circ} \mathrm{C}$ range interval. Nevertheless, it becomes stable from $300{ }^{\circ} \mathrm{C}$ and up. The small yield improvement between $300{ }^{\circ} \mathrm{C}$ and $320{ }^{\circ} \mathrm{C}$ can be explained by the formation of a great concentration of refractory intermediates (acetic acid essentially). See figure 5.

The molecule structure, its thermal stability as well as its organic carbon content affect the oxidation process. More thermodynamically stable molecules need higher activation energy for their oxidation. The more a molecule is thermodynamically stable, the more it will need an important activation energy for its oxidation. The reaction begins by the attack of the dissolved oxygen on one of the weakest $\mathrm{C}=$ $\mathrm{H}$ bonding of the molecule [21]. Therefore, the structure of the molecule determines the nature of the reaction by-products that are formed in the course of the degradation process.

The relatively minor effect of the reaction time in the chosen study area can be explained by the fact that radical reactions include initiation, propagation and termination steps. These steps take place rapidly enough in the first minutes of the oxidation process ending with the formation of $\mathrm{CO}_{2}$ as well as other organic compounds. Afterwards, there is a degradation phase of the intermediates, which is very slow. The strong initial substrate concentration bring about the formation of a high concentration of reaction by-products, which consequently slow the degradation process down and decrease the yielding.

\section{Conclusion}

The WAO can be used for the nuclear waste treatment. It appreciably improves the abatement of the organic matter and the reduction of the volume of the waste before its storage.

This study shows that different parameters act upon the WAO reaction at different degrees. Very good degradation yields can be obtained for reaction temperatures around $300{ }^{\circ} \mathrm{C}$, reaction times in the order of 20 to 30 minutes and air pressure superior to 80 bars.

In order to improve this yield, we envisage a continuous system, which is currently under study in our laboratory.

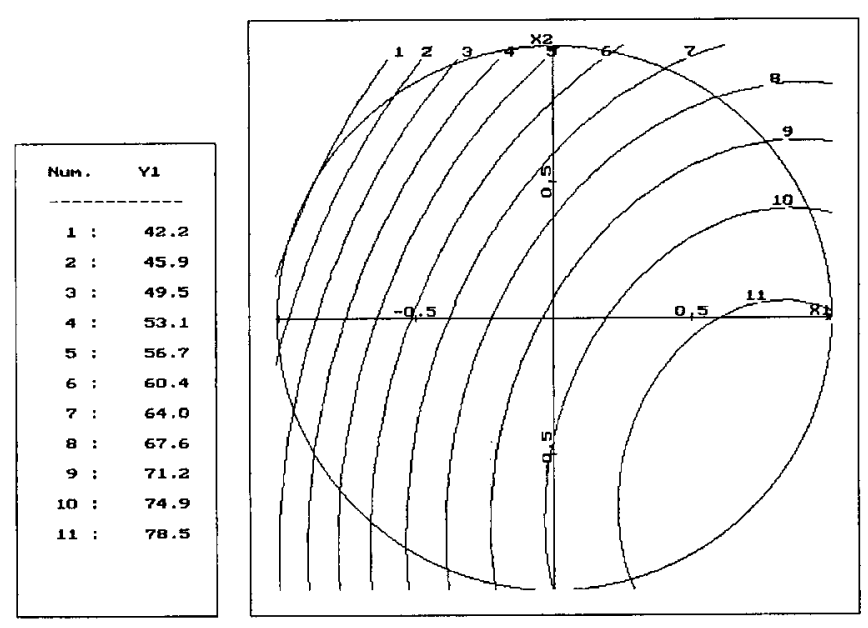

Fig. 7. WAO of trifluorothenoylacetone: variation of the TOC yield versus reaction temperature and initial substrate concentration.

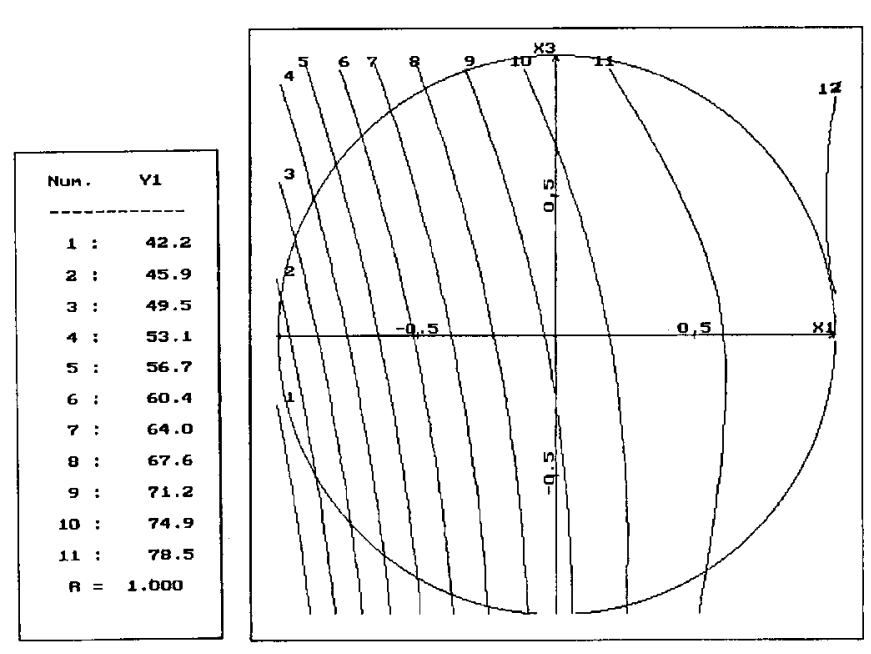

Fig. 8. WAO of trifluorothenoylacetone: variation of the TOC yield versus reaction temperature $\left(X_{1}\right)$ and reaction time $\left(X_{3}\right)$.
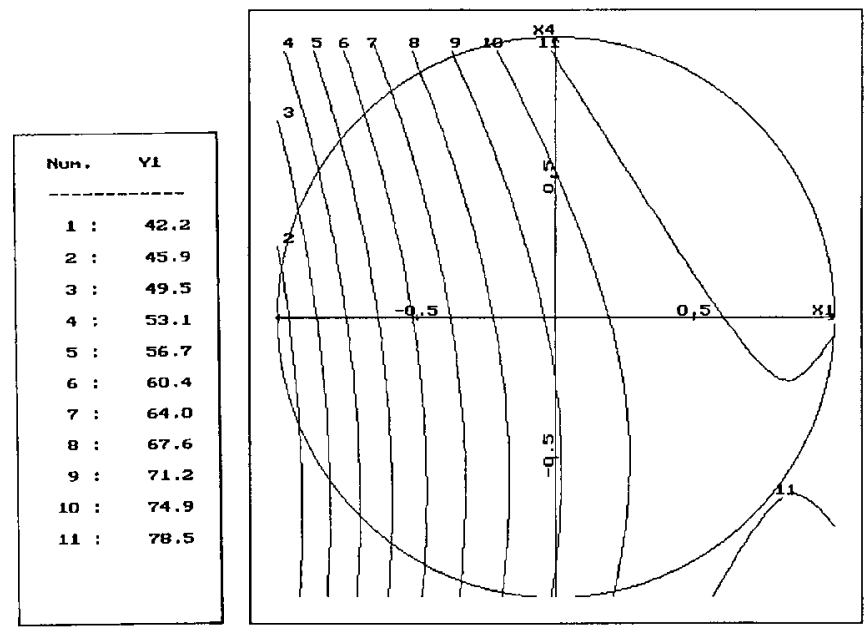

Fig. 9. WAO of trifluorothenoylacetone: variation of the TOC yield versus reaction temperature $\left(X_{1}\right)$ and oxygen partial pressure $\left(X_{4}\right)$. 
In this system, the contact between the oxidizing mixture and the substrate is carried out several times. This system has the advantage of initiating the beginning of the reaction at every contact and therefore it allows a better degradation of the compounds.

\section{Abbreviations}

$\mathrm{TOC}_{\text {in }}$ Total organic carbon in solution at the initial state.

$\mathrm{TOC}_{\mathrm{f}}$ Total organic carbon in solution at the end of the reaction.

$\triangle T O C$ Degradation yield according to the total organic carbon in solution.

$X_{i} \quad$ Coded variable $i$.

$X_{1} \quad$ Temperature.

$X_{2} \quad$ Reaction time.

$X_{3} \quad$ Volume of the solution in the reactor.

$X_{4} \quad$ Initial substrate concentration.

$X_{5} \quad$ Agitation speed.

TTA Trifluorothenoylacetone.

EDTA Ethylenediaminetetraacetic acid.

TBP Tributylphosphate.

TDA Tridodecylamine.

\section{References}

1. Antonini, G.; Gislais, P. Traitement thermique des Déchets industriels, Technique et Documentation - Lavoisier, Paris, 1995.

2. Dawans, F. Le traitement des déchets polymères, La valorisation énergétique ou chimique, Environnement et Technique/info-déchets $\mathrm{N}^{\circ} 128$ mai 1993; p 32-42.

3. Merry, J. L. L'eau, l'industrie, les nuisances 1989, 133, 5254.

4. Johnston, J. B.; Hannah, R. E.; Cunningham, V. L.; Daggy, B. P.; Sturm, F. J.; Kelly, R. M. Biotechnology 1988, 6, 14231427.

5. Freeman, H. M.; Olexlay, R. A.; Obercraker, D. A.; Mournigan, R. E. J. Hazard Mater 1987, 14, 103-117.
6. Klay, H. R. Installation d'oxydation en phase liquide pour l'épuration des eaux usées, La Technique moderne, juillet août 1989; pp 56-58.

7. McGinnis, G. D.; Wilson, W. W.; Prince, S. E.; Chen, C. Ind. Eng. Prod. Res. Dev. 1983, 22, 633-636.

8. Mishra, V. S.; Mahajani, V. V.; Joshi, J. B. Ind. Eng. Chem. Res. 1995, 34, 2-48.

9. Hao, O. J.; Phull, K. K.; Chen, J. M.; Davis, A. P. J. of Hazardous Mater. 1993, 34, 51-68.

10. Copa, W. M.; Randall, T. L. Wet Oxidation of propellants and propellant Wastewater, Zimpro Passavant; Rothschild, W I 1990.

11. Holman, D. J. Process Options for Treatment of Organic Containing ILWs by Wet Oxidation, Radioactive Waste Management 2, BNES, London, 1989.

12. Kalman, J.; Palùai Gy.; Szebényi, I. Wet Oxidation Of Toxic Sludge, Proceeding of the LAWTRC's "the design and operation of large wastewater treatment plants", International conference, Budapest, 1987.

13. Rappe, G. C. Environ. Prog. 1985, 4(1), 56-60.

14. Dietrich, M. J.; Randall, T. L.; Canney, P. J. Environ. Prog. 1985, 4(3), 174-7.

15. Foussard, J. N. Étude de l'Oxydation en phase aqueuse à température et à pression élevées: Transfert de l'oxygène moléculaire et Cinétique de dégradation des acides carboxyliques légers, Thèse de Docteur-Ingénieur. Octobre 1983, INSA Toulouse France.

16. Chakchouk, M.; Deiber, G.; Foussard, J. N.; Debellefontaine, H. Env. Tech. 1995, 16, 645-655.

17. Dubois, M. A. Degradation des Résines échangeuses d'ions par Oxydation par Voie Humide en Conditions sous-critique et supercritique; Thèse de Docteur de l'Université de Provence, Décembre 1994; p 117-119.

18. Pessik, A. Méthodologie de la recherche expérimentale: Propriétés et caractéristiques des matrices d'expériences pour les modèles polynoniaux du second degré, Thesis, Université d'Aix-Marseille III, 1995; p 123-125.

19. Mathieu, D.; Phan-Tan-Luu, R. Logiciel NEMROD, version 2.0. 1994, Laboratoire de prospective réactionnelle et d'analyse de l'information, Université d'Aix-Marseille III.

20. Delvin, H.; Harris, I. J. Mechanism of the Oxidation of Aqueous Phenol with Dissolved Oxygen, Ind. Eng. Chem. Fundam. 1984, 23, 387-392.

21. Jouffert, M. Les Oxydations radicalaires par l'air ou l'oxygène en phase liquide ou gaseuse Recueil des Conférences, Aspects théoriques de la catalyse d'oxydation; Lyon Ecully 18-12 mai, 1978. 